\title{
Microstructures of Microcrystalline Silicon Solar Cells Prepared by Very High Frequency Glow-Discharge
}

\author{
J. Dubail, E. Vallat-Sauvain, J. Meier, S. Dubail and A. Shah \\ Institut de Microtechnique (IMT), A.L. Breguet 2, Université de Neuchâtel, \\ CH-2000 Neuchâtel, Switzerland.
}

\begin{abstract}
The microstructure of two different $\mu \mathrm{c}-\mathrm{Si}: \mathrm{H}$ solar cells was studied by Transmission Electron Microcopy (TEM). At the micrometer scale, a difference in the grain structure is observed close to the $\mathrm{ZnO}$ substrate: cracks are found in the cell deposited with the higher silane concentration. Surprisingly, the cell with the cracks close to the transparent conductive oxide shows the largest $\mathrm{V}_{\mathrm{OC}}(530 \mathrm{mV})$ and $\mathrm{FF}(68 \%)$. These first studies reveal that microstructures of fully microcrystalline silicon devices may show a quite large variation with corresponding effects in solar cell performance.
\end{abstract}

\section{INTRODUCTION}

Hydrogenated microcrystalline silicon $(\mu \mathrm{c}-\mathrm{Si}: \mathrm{H})$ is a promising new photovoltaic (PV) absorber material. Thin films of this material have been grown to fabricate single-junction $\mu \mathrm{c}-$ $\mathrm{Si}: \mathrm{H}$ and micromorph (a-Si:H/ $\mu \mathrm{c}-\mathrm{Si}: \mathrm{H})$ tandem solar cells, providing thereby encouraging results [1-3]. While detailed characteristics of microcrystalline absorber material in terms of absorption behavior, transport properties, device performance and stability are available, only very little is known about the internal structure of this material. Recently, we have reported, in a transmission electron microscopy (TEM) study of undoped $\mu \mathrm{c}-\mathrm{Si}: \mathrm{H}$ films deposited on glass substrates that $\mu \mathrm{c}-\mathrm{Si}: \mathrm{H}$ shows a surprisingly large variation of internal microstructures $[4,5]$. In this former study we found that the morphology is strongly dependent on the hydrogen to silane dilution ratio used during deposition.

On the other hand, it is known that the microstructure is also critically substrate-dependent, at least during the early stage of growth [6-8]. In case of entirely microcrystalline p-i-n devices deposited on a transparent conductive oxide (TCO), not only the microstucture but also the quality of the electrical contact is essential for obtaining satisfactory solar cell performance. Especially the initial crystalline growth of the $\mu \mathrm{c}-\mathrm{Si}: \mathrm{H}$ p-i interface on the TCO is critical for a good working device. Sofar, only very little has been reported on the microstructure of entire $\mu \mathrm{c}-$ $\mathrm{Si}: \mathrm{H}$ cells. This present work is a first attempt to focus on the structure of microcrystalline $\mathrm{p}-\mathrm{i}-\mathrm{n}$ devices by using TEM investigations. We show results of TEM cross-sections of two $\mu \mathrm{c}-\mathrm{Si}: \mathrm{H}$ cells with conversion efficiencies of 6 and $7 \%$, respectively. These two devices were deposited under slightly different deposition conditions, using in both cases the Very High Frequency Glow Discharge technique (VHF-GD) [9].

\section{EXPERIMENTAL Cell deposition}


This study is based on two microcrystalline single-junction p-i-n solar cells named Cell A and Cell B. A fully $\mu \mathrm{c}-\mathrm{Si}: \mathrm{H}$ p-i-n structure was grown by VHF-GD, on a rough $\mathrm{ZnO}$ (TCO transparent conductive oxide) layer deposited by us on a glass substrate.

The doped layers of both cells investigated were deposited using the same deposition parameters. Both $<i>$ layers were deposited at a plasma excitation frequency of $180 \mathrm{MHz}$. Microcrystalline growth was obtained using a silane concentration $\mathrm{SiH}_{4} /\left(\mathrm{SiH}_{4}+\mathrm{H}_{2}\right)$ of 5.6 and $5 \%$, respectively, at a deposition temperature of $250^{\circ} \mathrm{C}$. We observe that the hydrogen to silane dilution ratio critically affects solar cell performance [3]. As already reported on our film dilution series deposited on glass substrates, this deposition parameter also influences the microstructure $[4,5]$. On the other hand, in a superstrate solar cell structure consisting of glass/TCO/p-i-n $\mu \mathrm{c}-\mathrm{Si}: \mathrm{H}$, the critical $\mathrm{p}$ - $\mathrm{i}$ interface is formed at the beginning of $\mu \mathrm{c}-\mathrm{Si}: \mathrm{H}$ deposition. In this case, the condition of the substrates certainly very decisive for obtaining an optimally grown p-i interface. The cells were characterised under AM 1.5 illumination and by spectral response measurements. Even if both cells were not optimised with respect to ultra-thin p-window or a high reflectivity of the back reflector, they still have conversion efficiencies between 6 and 7\%. In this first attempt to investigate the microstructure of our cells, we aimed at choosing cells deposited under rather similar conditions, but exhibiting different electrical characteristics. Table I. shows the properties of the cells investigated by TEM.

Table I. Parameters of investigated solar cells.

\begin{tabular}{|c|c|c|}
\hline Cell parameter & Cell A & Cell B \\
\hline $\mathrm{V}_{\mathrm{OC}}[\mathrm{mV}]$ & 530 & 486 \\
\hline $\mathrm{J}_{\mathrm{SC}}\left[\mathrm{mA} / \mathrm{cm}^{2}\right]$ & 16.6 & 22.5 \\
\hline $\mathrm{FF}[\%]$ & 68 & 64 \\
\hline$<\mathrm{i}>$ layer thickness $[\mu \mathrm{m}]$ & 1.4 & 5.4 \\
\hline deposition rate $[\AA \mathrm{A} / \mathrm{s}]$ & 5.2 & 4.6 \\
\hline
\end{tabular}

\section{TEM sample preparation}

Both cells were prepared as cross-sections for TEM examination using a technique described in [10]. In order to achieve electron transparency, two pieces of the same specimen were glued head to tail (see Fig. 1). An special instrument named "Tripod" permits one to mechanically polish the "sandwich", thereby obtaining a corner with an angle as low as 0.6-0.8 . At the edge of the corner one gets then a thin enough zone (few $100 \mathrm{~nm}$ ), where electron transmission occurs. After this preparation step, an ion-beam-assisted cleaning and polishing procedure was applied. In our case, the advantage of this mostly mechanical preparation technique of thin-film cross-sections is the reduced ion-milling step [10].

In this preliminary study, we present our TEM observations made at low magnification (< $30000 \mathrm{x}$ ) in order to inspect the micrometric structure of our material. Bright field mode was used as well as dark field (DF) imaging. The two first diffraction rings were used to form dark field images. Indeed, we could qualitatively observe that the (220) diffraction rings yielded brighter DF images, indicating a (220) preferential growth orientation within both $\langle i\rangle$ layers of the cells. 


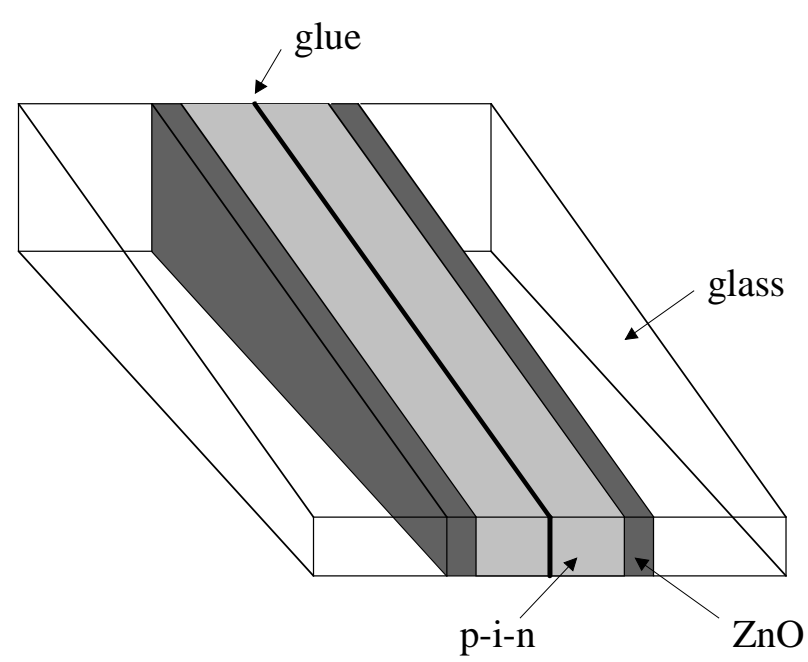

Figure 1. Sketch of a sample preparation for TEM observations.

\section{RESULTS AND DISCUSSION}

Both cells shows a significant difference in the microstructure, although only a slight intentional change in the deposition parameter was applied (with respect to $\mathrm{H}_{2}$ dilution of silane). Figs. 2 and 3 represent the bright and dark field cross-sections of Cell A and Cell B, respectively. It has to be pointed out that the different characteristics of the two structures can be seen even at lower magnification.

At the bottom of Figs. 2 and 3 we can observe the teeth-shaped zinc oxide substrate over which our cells were grown in the upwards direction. On the top of each picture one can observe the as-deposited roughness of our $\mu \mathrm{c}-\mathrm{Si}: \mathrm{H}$ p-i-n cells. It seems that this surface roughness is not much affected by the initial roughness of the TCO substrate. The growth of the <i>-layer smoothens the roughness of the substrate. This may have a beneficial effect on light-trapping properties of the cell.

The structure of the <i>-layer consists of an aglomerate of small microcrystallites (dark spots in Fig. 2). The grains (i.e. aglomerates) have a diameter of several hundreds of nanometers and run across the whole thickness of the device. Close to the substrate, these aglomerates are loosely packed, resulting in visible cracks, appearing brighter on Fig. 2. These cracks may consist of an amorphous phase or may just be voids. Towards the top of the cell, the microstructure becomes denser. Somewhat similar growth morphology has been observed for ntype layers deposited on flat crystalline silicon substrates [11].

In Fig. 3, the microcrystallites within the aglomerates of Cell B are evidenced by the dark field imaging conditions, where crystallites satisfying diffraction conditions appear brighter. Their diameter is of a few tens of nanometers, while their length depends on their location whithin the cell. Indeed, close to the $\mathrm{ZnO}$ substrate, the crystallites grow perpendicular to the $\mathrm{ZnO}$ facets; their length is equal to several tens of nanometers. However further away, they grow perpendicular to the average substrate plane, and their length can reach several micrometers.

The characteristic features of both microstructures are sketched in Fig. 4. 


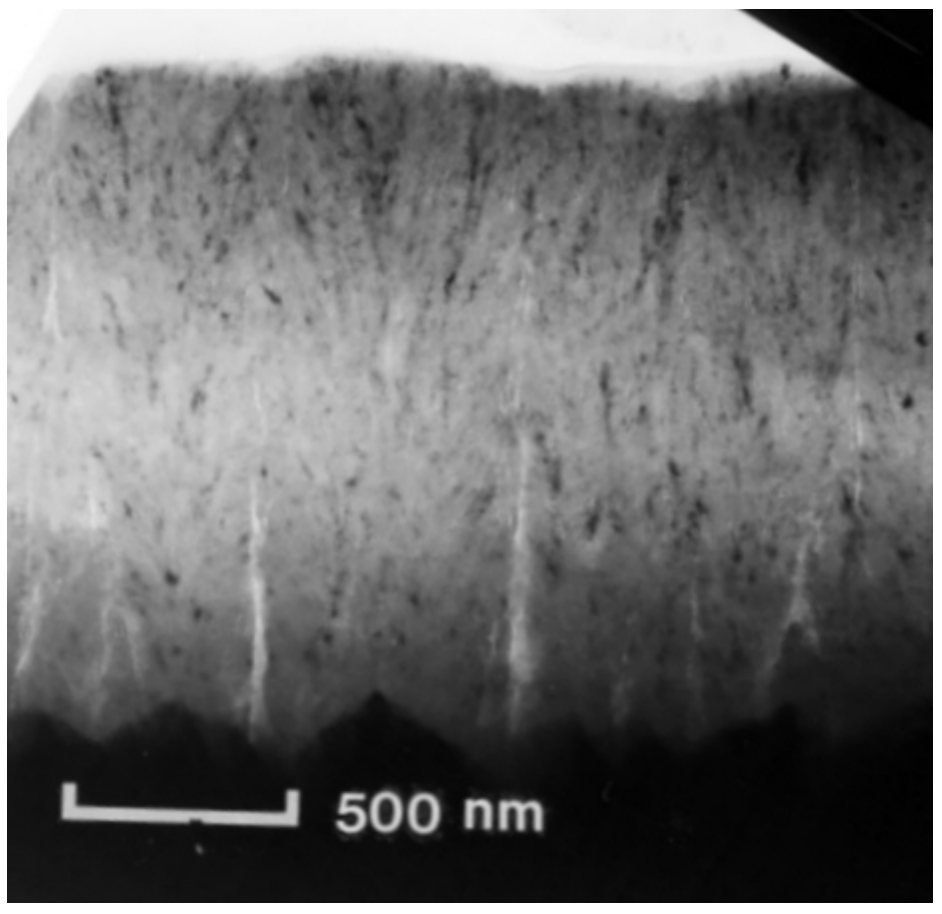

Figure 2. TEM bright field cross-section micrograph of cell A. Voids and/or cracks appear brighter.

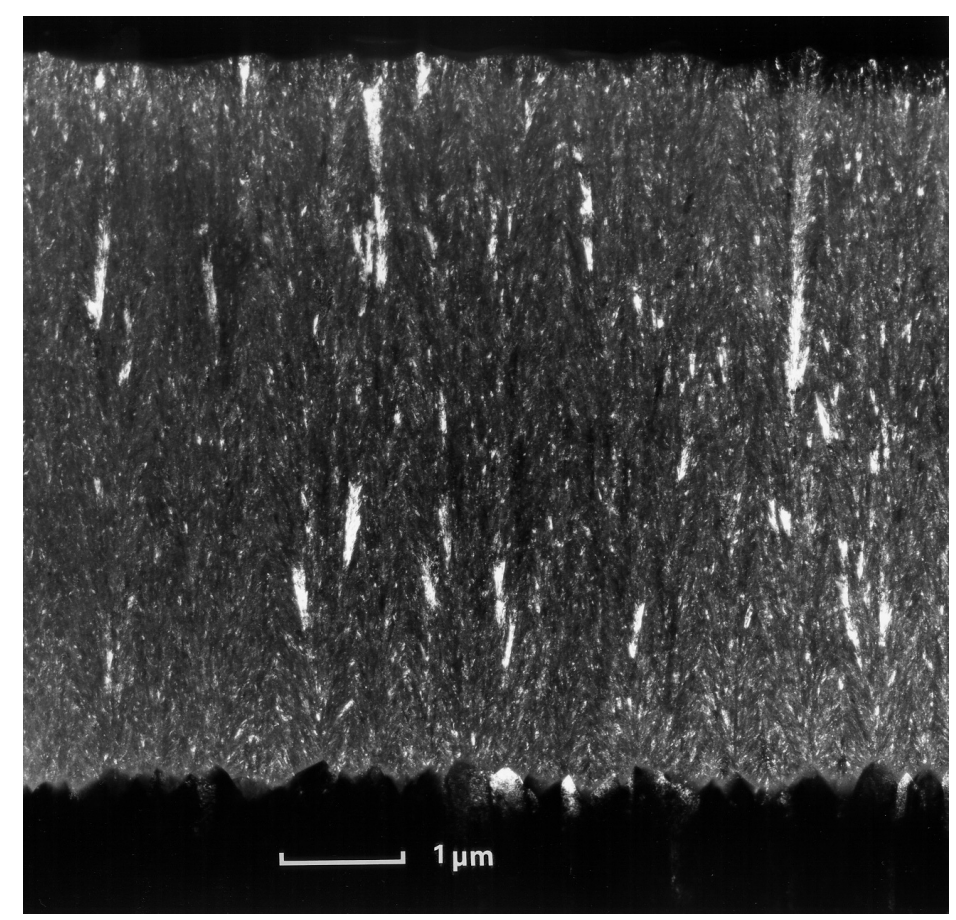

Figure 3. TEM dark field cross-section micrograph of cell B. Microcrystallites best satisfying diffraction conditions appear bright. 


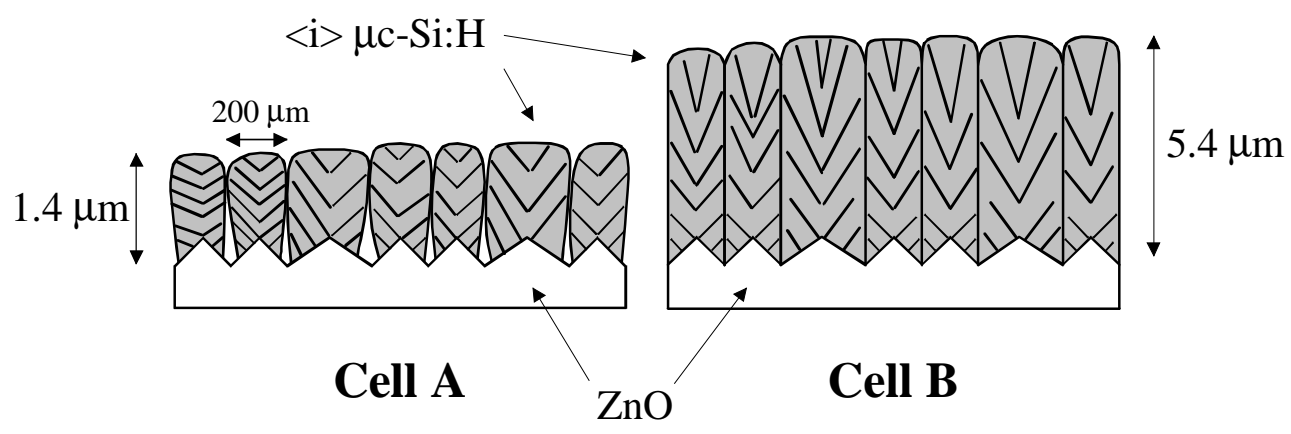

Figure 4. Schematics of both TEM micrographs given above.

In contrast to Cell A (Fig. 2), cracks are not observed in Cell B. But the aglomerate size is determined in both cells by the substrate surface geometry. Indeed, as can be observed in Fig. 2, grain (aglomerate) boundaries start in the bottom valleys, as already observed by [6]. This suggests that in both cases aglomerates start to grow at the top of $\mathrm{ZnO}$ pyramids. If the presence of cracks in Cell A is only related to the difference in deposition conditions (in our case, the hydrogen to silane dilution ratio) remains sofar unclear and needs further studies.

Both cells exhibit sub-structure (microcrystallites) growing perpendicular to the $\mathrm{ZnO}$ facets [6]. In Cell A, the direction of microcrystallite growth remains constant over the whole cell thickness. In Cell B, which is more than three times thicker, the direction of crystallite growth changes as the cell becomes thicker. Cell B exhibits a much more denser microstructure. Here, only $1 \mu \mathrm{m}$ away from the $\mathrm{ZnO}$ interface we observe in both cells adjacent grains perpendicular to the substrate. The diameter of these large grains is of the order of a few hundreds of $\mathrm{nm}$; the grains run all the way across the device.

Electrical characteristics of cells A and B were given in Table I. As the cells have quite different thicknesses, we cannot compare the current densities. Thus, our two cells can be compared only w.r.t. $\mathrm{V}_{\mathrm{OC}}$ and FF. Surprisingly, the $\mathrm{V}_{\mathrm{OC}}$ is higher in the Cell A, which exhibits voids at the $\mathrm{ZnO} / \mathrm{p}-\mathrm{i}$ interface. This suggests that a high $\mathrm{V}_{\mathrm{OC}}$ is due to features at lower scales (nanometer or atomic range) such as the quality of the p-i interface / contamination or the quality of the passivation of the grain boundaries. Such features cannot be observed on our medium magnification micrographs. On the other hand, the study of the microstructure and electrical properties of $\mu \mathrm{c}-\mathrm{Si}: \mathrm{H}$ solar cells thickness series may be a way to correlate sub-structure effects (observed in cells A and B) with device performance.

\section{CONCLUSIONS}

Two microcrystalline silicon single-junction $\mathrm{p}-\mathrm{i}-\mathrm{n}$ solar cells with conversion efficiencies of 6 and 7\% have been prepared in cross-sections for TEM analysis. Medium magnification observation of both samples already permits one to draw the following three main conclusions:

1. A small change in the deposition parameters and different cell thicknesses leads to quite different microstructures.

2. The surface topology of the substrate seems determinant at the early stage of growth for the size of $\mu \mathrm{c}-\mathrm{Si}: \mathrm{H}$ grains. In our case we identify that grains are adjacent in the valleys of the underlaying $\mathrm{ZnO}$ layer. We therefore suggest that the nucleation of each grain takes place at 
the top of a zinc oxide pyramid. In Cell B, at the sub-grain (crystallites) scale, the initial growth occurs perpendicular to the $\mathrm{ZnO}$ facets, and becomes perpendicular to the substrate plane, i.e. parallel to the current path, as growth proceeds.

3. In cell $\mathrm{A}$, the presence of micrometric cracks between grains is not harmful for cell operation and the value of $\mathrm{V}_{\mathrm{OC}}$ is well over $500 \mathrm{mV}$.

This work was a first attempt to observe the microstructures of entire $\mu \mathrm{c}-\mathrm{Si}: \mathrm{H}$ solar cells as a function of the silane dilution concentration used for deposition. This approach is encouraged by the observation of microstructural variations of the material (i.e. at the micrometer scale) for small changes in the deposition parameters and variable cell thickness. At this stage, the effect of material microstructure on the electrical properties of the devices are still far from being elucidated.

\section{ACKNOWLEDGMENTS}

J.D. would like to thanks personnally Mrs. D. Laub from CIME-EPFL in Lausanne (Switzerland) for her help in preparing the samples for TEM observation, Dr. M. Dadras for his help for TEM manipulations and Mrs. M. Leboeuf for her help in printing the photographs. IMT expresses its gratitude to Prof. F. Stöckli for granting access to the TEM facilities.

We acknowledge financial support from the Swiss Federal Office for Energy BEW/OFEN under grants 2757 and 19431 as well as the Swiss National Science Fund under grant FN52337.

\section{REFERENCES}

[1] J. Meier, R. Flückiger, H. Keppner, A. Shah, Appl. Phys. Lett. 65, p. 860 (1994).

[2] J. Meier, S. Dubail, R. Flückiger, D. Fischer, H. Keppner, A. Shah, Proc. of 1st WCPEC, p. 409, (1994).

[3] J. Meier, E. Vallat-Sauvain, S. Dubail, U. Kroll, J. Dubail, S. Golay, L. Feitknecht, P. Torres, S. Fay, D. Fischer and A. Shah, to be publ. in Solar Energy Mat. and Solar Cells (presented at PVSEC-11, 1999).

[4] E. Vallat-Sauvain, U. Kroll, J. Meier, A. Shah, J. Appl. Phys. 87, p. 3137 (2000).

[5] E. Vallat-Sauvain, U. Kroll, J. Meier, N. Wyrsch and A. Shah, to be publ. in J. Non-Cryst. Solids (presented at ICAMS 18, 1999).

[6] H. Yamamoto, M. Isomura, M. Kondo and A. Matsuda, Techn. Digest of PVSEC-11, p. 231, (1999).

[7] P. Torres, H. Keppner, R. Flückiger, J. Meier, A. Shah, Proc. 12th EPVSEC, p. 132 (1994).

[8] J. Koh, Y. Lee, H. Fujwara, C.R. Wronski, R.W. Collings, Appl. Phys. Lett. 73, p. 1526 (1998).

[9] H. Curtins, N. Wyrsch, A. Shah, Electron. Lett. 23, p. 223 (1987).

[10] J. Benedict, R. Anderson and S. J. Klepeis, Mat. Res. Soc. Symp. Proc. Vol. 254, pp. 121140 (1992).

[11] L. Houben, M. Luysberg, P. Hapke, R. Carius, F. Finger and H. Wagner, Phil. Mag. A 77(6), pp. 1447-1460, (1998). 